\title{
Study on the Interaction Development between College Students' Leisure Sport and Fashion Pursuit
}

\author{
Qin Li and Huang Zhen \\ NanChang Institute of Science and Technology,Nanchang,330108
}

Keywords: College students; leisure sports; E-sports; interaction

\begin{abstract}
As the mainstream choice for college students in fitness, leisure sportnot only affectsthe choice of lifestyle and living quality improvement of undergraduates, but also is an important form of lifelong education and lifelong sport. This paper presents the interactive relation betweenleisure sports and fashion and the influential factors to put forward the countermeasure to guide college students to pursue the healthy and interactive development of leisure sports and fashion pursuit.
\end{abstract}

\section{Introduction}

With the reform and development of physical education in colleges and universities in our country, new changes have taken place in the content of college students' sports life. There are many leisure sports events with popularity, novelty and openness, such as billiards, tennis, archery, Sanda, Latin dance, camping, rock climbing, yoga, bowling, taekwondo and so on. These elegant and stylish sports fitness modes can meet the physiological and psychological needs of college students, promote the construction of spiritual civilization on campus, guide the development direction of college students' humanistic quality, and promote theundergraduates' healthy lifestyles and form lifelong physical habits, thus they are conducive to the construction of university campus culture, which is in line with the reform of teaching contents and methods of physical education in higher institutions. So, it is the important issue thatthe current college students' physical education should concern abouthow to use the correct theory to guide students' practice better and make college students fitness activities more sensible and healthier. The current situation of college students' leisure sport activity and fashion pursue in Hubei Province is investigated, and the interactive relationship between them and the influencing factors are initially discussed, and some countermeasures to promote its good interactive development is put forward. It aims to provide the reform and development of physical education in colleges and universities with reference.

\section{Discussion on Leisure Sports from Cultural Perspective}

From a cultural point of view, leisure sports can be regarded as a kind of free spirit experience of human beings. It has rich cultural heritage that supports our spiritual life. Its deep cultural significance is the most important part to explore its value. Leisure is hailed as a cultural foundation and has cultural spirit. It plays a promoting and balancing role in the process of social development. It has the function of making up and correcting human's sensibility, behavior and role.

Sports culture is a special kind of culture which is manifested in all sports phenomena and sports activities. Leisure culture is a special field of cultural expression and the basic unit for constructing the entire social culture. The leisure sports culture is derived from the combination of sports culture and leisure culture. Leisure sports culture is one of the constructions of human social cultures and is a special cultural form with cross and compound characteristics.

Experts and scholars make different interpretations on the connotation of leisure sports culture from different aspects. Some scholars think that leisure sports culture is free choice according to people's interests by using leisure time. It's the sum of the ideas and attitudesfor self-enjoyment and development.

In virtue of the definition of culture and scholars' description of leisure sports culture, the author thinks that leisure sports culture is a unified body of material culture, institutional norms, values and behaviors formed in the process of leisure practiceby taking sports as a carrier. In the material and 
cultural aspects, leisure sports culture is rich in content, including all artificialities, such asthe places, equipment, facilities for all the leisure sports activities, and natural objects that need to be reworked according to the needs of sports activities. In the aspect of social system, sports laws and regulations, and the activity mode and rule requirements of the leisure sports are thecode of conduct for participants. In the aspect of values, people can establish a correct view of sports and leisure, deepen their attitudes and perceptions towards sportsand understand the leisure value and meaning.

\section{Interactive Relationship between Leisure Sports and Fashion Pursue}

People have different views on the definition of leisure sports. After gathering the view the concept of leisure sports of many scholars, the author thinks "leisure sports is a meaningful modern way of lifecarried out in free time with a certain form of physical activity as a means to produce the best psychological experience, and people are not subject to the strict rules of activity, and actively pursue the inner experience, so that individuals can get the physical and mental rest, relax and enjoyment." The definition is quite general and representative. Just as the early leisure sports scholars defined, introduced and evaluated the concept of leisure sports as s"leisure sports is a kind of construction with at least three dimensions and is a social phenomenon and mode of existence of sports , but also one of the main ways of social leisure."And the relatively complete summary and definition just correspond with it.

A lot of fashionable, innovative and open leisure sports such as billiards, tennis, archery, sanda, Latin dance, camping, rock climbing, yoga, bowling, taekwondo, etc. emerge in leisure sports. These elegant fashion sports fitness modes can meet the college students' physiological and psychological needs, promote the construction of spiritual civilization on campus, guide the development direction of humanistic quality of college students and promote healthy lifestyles and form lifelong physical habits for college students. It is beneficial for the construction of university campus culture andis consistentwith the teaching contents and methodology reform in PE class of colleges and universities. The correct theory can better guide students' practice, and promote college students' fitness activities wiser and healthier.

\section{Interactive Relationship Between Leisure Sports and e-Sports}

The progress and development of leisure sports just requires that the participants have a certain amount of free time and a certain share of the distribution. Through the summary of the conceptual elements and classification criteria of leisure sports, it is considered that "the leisure sports activities are divided into seven categories according to the purpose and motivation of sports activities: fitness shaping, entertainment, competition, recreational relaxation,social contact, novelty explorationand seeking excitement." E-sports belongs to the category of competition.

For a long time, people have some different idea about the definition of e-sports. "E-sports is a interpersonal competition sport based on information technology as the core, guided by the rules of sports, using hardware and software as the device It can exercise and improve participants' thinking ability, reaction ability, coordination ability of eyes and limbs and willpower, etc. From this definition, it is not difficult to see that e-sports is the perfect combination of computer technology and competitive sports .Electronic sports mainly include three basic elements: one is electronic; the other is competitive sports, which includes two types: virtual reality and fictional sports; the third is the competition between people (team) and people (team). Thus, it can be seen that e-sports is different from the reality of competitive sports, but also different from online games.

With China's e-sports clubs in the international competitions have repeatedly defeated South Korea, the introduction of a large number of Korean aids is the shortcut of most Chinese clubs, which to some extent, can promote the development of the gaming industry and the improvement ofoverall level. But on a long view, lack of reserves of newcomers will be a major obstacle to its development. 


\section{Conclusion}

From a cultural point of view, leisure sports can be regarded as a kind of free spirit experience of human beings. It has rich cultural heritage that supports our spiritual life.Its deep cultural significance is the most important part to discuss its value. Leisure is hailed as a cultural foundation and has cultural spirit. It plays a promoting and balancing role in the process of social development. It has the function of making up and correcting human's sensibility, behavior and role.

Project funding: Humanities and social science research project funding of Nanchang Institute of Science and Technology (NGRW-17-15)

\section{References}

[1] Sun G. Application of Digital Guidance Technology in Sports Leisure Equipment Design[J]. Atlantis Press, 2015.

[2] Lin L. Discussion on the Development of the Leisure Sports Industry in China in Light of the Interaction Relationship between Culture and Industry[J]. Journal of Beijing Sport University, 2006.

[3] Zhan M Y. Research on the development path of leisure sports from leisure vision[J]. Heilongjiang Science, 2017.

[4] Jing S U, Zhang Q F, Wang Q. Theoretical study of cross-coupling relationship between nation-wide fitness and leisure sports[J]. Journal of Wuhan Institute of Physical Education, 2010.

[5] Wang G X, Jin-Long L I, LIUYing-hui. On the Relationship between Social Progress in the 20th Century and Mankind's Sports Leisure Requirement[J]. Journal of Beijing Sport University, 2009.

[6] Sun Y. Relationship Between Leisure Physical Activity And Quality Of Life For College Students[J]. Journal of Anhui Sports Science, 2011.

[7] Shao M H, Department B, University Z S. Study on Interactive Model of Sports Leisure Industry and Tourism in Hangzhou Fuyang[J]. Zhejiang Sport Science, 2014.

[8] Jinying Y U. The Interaction between Leisure Sport Consumption and Media[J]. Journal of Fuqing Branch of Fujian Normal University, 2007.

[9] Min J, Jin H. Analysis on Essence, Types and Characteristics of Leisure Sports[J]. Modern Applied Science, 2010， 4(7).

[10] Wu K, Cheng J, Ye M, et al. Influence of cultural factors on leisure sports behavior of city dwellers in Shenzhen[C]// International Conference on Computer Science and Service System. IEEE, 2011:2290-2293.

[11] Kleiven J. Measuring leisure and travel motives in Norway: replicating and supplementing the leisure motivation scales.[J]. Tourism Analysis, 2005， 10(2):109-122.

[12] Thorpe H, Ahmad N. Youth, action sports and political agency in the Middle East: lessons from a grassroots parkour group in Gaza.[J]. International Review for the Sociology of Sport, 2015, 41(6):198-200. 